\title{
Cough as a neurological sign: Does it worth it?
}

\author{
Mohammed Al-Biltagi ${ }^{1}$, Adel Salah Bediwy ${ }^{1}$, and Nermin Saeed $^{2}$ \\ ${ }^{1}$ Tanta University Faculty of Medicine \\ ${ }^{2}$ Salmaniya Medical Complex Pathology Department
}

February 17, 2021

\begin{abstract}
Cough is one of the most common complaints that lead patients to see a doctor. It is not only a basic respiratory sign but also an important neurological sign. There are 3 main types of cough: reflex cough (type I), voluntary cough (type II), and evoked cough (type III). Reflex cough sensitivity may be increased in many neurological disorders, such as space-occupying lesion of the brainstem, medullary lesions secondary to type I Chiari malformations, tics disorders such as Tourette's syndrome, somatic cough, neurodegenerative disorders of the cerebellum, and chronic vagal neuropathy due to allergic and nonallergic diseases. On the other hand, cough sensitivity decreases in the cerebral hypoxia, cerebral hemispheric stroke with a brainstem shock, dementia due to Lewy body disease, Parkinson's disease, amyotrophic lateral sclerosis, multiple sclerosis, and peripheral neuropathy such as hereditary sensory and autonomic neuropathy type IV, diabetic neuropathy, vitamin B12, and folate deficiency. The earcough reflex of Arnold's nerve, syncopal cough, cough headache, opioid associated cough and cough-anal reflex are signs that can help in the diagnosis of underlying neurological disorders. The cough reflex test is a quick, easy, and inexpensive test that can be performed during the cranial nerve exam. In this article, we have discussed cough reflex testing and various neurological disorders that increase or decrease cough sensitivity.
\end{abstract}

\section{Title: Cough as a neurological sign: Does it worth it?}

\section{Authors:}

1. ; MD, PhD (Ped); Pediatric Department, Faculty of Medicine, University, .

2. Prof Adel Salah Bediwy, MD, PhD Chest Disease, Chest Disease Department, Faculty of Medicine, Tanta University, Egypt.

3. Dr Nermin Kamal Saeed, ABMM, Pathology Department, Slamanyia Medical Complex, MOH, Bahrain.

\section{Corresponding Author Address}

Prof. Mohammed Al Biltagi; Professor of Pediatrics; Pediatric Department, Tanta University, Egypt. mbelrem@hotmail.com. : +97339545472

Pediatric Department, Faculty of Medicine, Tanta University, Al Bahr Street, Tanta, Algharbia Province, Egypt

\section{Keywords:}

Cough reflex, Neurological disorders, Cerebral disorders, cerebellar disorder, Vagal Neuropathy.

Running Title: Cough as a Neurologic Sign

Conflict of Interest: no conflict of interest to be disclosed.

Funding: no funding support 


\begin{abstract}
:
Cough is one of the most common complaints that lead patients to see a doctor. It is not only a basic respiratory sign but also an important neurological sign. There are 3 main types of cough: reflex cough (type I), voluntary cough (type II), and evoked cough (type III). Reflex cough sensitivity may be increased in many neurological disorders, such as space-occupying lesion of the brainstem, medullary lesions secondary to type I Chiari malformations, tics disorders such as Tourette's syndrome, somatic cough, neurodegenerative disorders of the cerebellum, and chronic vagal neuropathy due to allergic and nonallergic diseases. On the other hand, cough sensitivity decreases in the cerebral hypoxia, cerebral hemispheric stroke with a brainstem shock, dementia due to Lewy body disease, Parkinson's disease, amyotrophic lateral sclerosis, multiple sclerosis, and peripheral neuropathy such as hereditary sensory and autonomic neuropathy type IV, diabetic neuropathy, vitamin B12, and folate deficiency. The ear-cough reflex of Arnold's nerve, syncopal cough, cough headache, opioid associated cough and cough-anal reflex are signs that can help in the diagnosis of underlying neurological disorders. The cough reflex test is a quick, easy, and inexpensive test that can be performed during the cranial nerve exam. In this article, we have discussed cough reflex testing and various neurological disorders that increase or decrease cough sensitivity.
\end{abstract}

\title{
Keywords:
}

Cough reflex, Neurological disorders, Cerebral disorders, cerebellar disorder, Vagal Neuropathy, Parkinsonism.

\section{Introduction:}

Cough is a forced exhalation effort against a closed glottis, which suddenly opens, expelling secretions and foreign bodies from the respiratory tract, making a characteristic sound. Cough is one of the most common complaints that prompt patients to seek medical attention. It is one of the most important protective mechanisms of the airways, indicating the presence of a potential or actual airway lesion and helping to clear secretions and foreign bodies from the airways (1). There are 3 main types of cough: reflex cough (type I), voluntary cough (type II), and evoked cough (type III), which is preceded by a coughing stimulus. Both reflex cough and voluntary cough trigger a similar mechanism of motor cough behavior. Cough is a reflex mediated predominantly by control centers in the respiratory areas of the brainstem, modulated by the cerebral cortex. Cough production proceeds through three coordinated phases: Inspiratory, compressive, and expiratory phases. It begins with contraction of the inspiratory muscles (drawing air into the lungs), closure of the glottis (creating subglottic pressure), and abduction of the vocal folds with forced expiration (forcing the glottis to open) with expulsion of secretions. However, the cough reflex is under voluntary control of higher neurological centers such as the cerebral cortex, which plays an important role in both the initiation and inhibition of coughing (2). The reflex has afferent sensory nerve fibers (mainly branches of the vagus nerve) that conduct afferent impulses diffusely to the spinal cord to reach the upper brainstem and pons. Other parts of the brain are associated with the proper function of the cough center in the medulla, such as the pontine respiratory group, lateral tegmental field, and deep cerebellar nuclei, which play a role in the pattern of cough formation and regulation. The efferent fibers conduct signals from the cough center to the diaphragm, abdominal wall, and muscles via the vagus, phrenic, and spinal motor nerves (3). Since the cough reflex is a reflex, it can be affected or influenced by various neurological disorders [Table 1]. Both reflex and volitional cough can be tested in various neurological and otolaryngological disorders. Different methods can test the sensitivity and efficiency of the cough reflex. Sensitivity can be assessed by the concentration or duration at which the cough can be evoked when exposed to variable concentrations and/or durations of nebulized aerosols of a cough-inducing substance (such as citric acid, L-tartaric acid, or capsaicin). However, there is considerable variability in the methods used in performing the test $(4,5,6)$. To assess the efficiency and strength of the cough, a group of Japanese scientists developed a device to measure cough strength while testing the cough reflex. They connected an electronic spirometer to an ultrasonic nebulizer through a special tube with a double lumen. The spirometer measures the peak cough flow of the provoked involuntary cough $(7)$. 


\section{Neurological Conditions Associated with Increased Cough Reflex Sensitivity:}

\section{Cerebral Disorders}

The urge-to-cough (UTC) is a cognitive sensation required to initiate and inhibit the reflexive cough elicited by stimuli lower than those normally required to elicit a motor cough. The cough is mediated by the cerebral cortical or subcortical regions (8). Cough that has no identifiable medical cause and does not respond to traditional medical measures used to be called psychogenic, habitual, or tic cough. Nowadays, the term "psychogenic" is replaced by "somatic" cough, and the term "habitual" has been replaced by "tic" cough, according to the Diagnostic and Statistical Manual of Mental Disorders, 5th (DSM-5) Edition (9).

The distinction between somatic and non-somatic chronic cough is occasionally challenging, as patients with chronic cough are more prone to psychomorbidities such as anxiety and depression, which in turn can trigger chronic cough. The diagnosis of somatic cough syndrome should only be made if the patient meets DSM-5 criteria, and not based on the presence or absence of a nocturnal cough or a cough with a barking/honking quality. Some categories of patients with somatic cough disorders (such as children) may benefit from nonpharmacologic trials of hypnosis or suggestion therapy (10). Tic-cough is a form of vocal or phonic tics characterized by coughing suddenly, briefly, intermittently, involuntarily, or semi-voluntarily. It may be associated with other motor or vocal tics such as throat clearing, sniffing, grunting, squealing, screaming, barking, blowing, and sucking (11). The diagnosis of a tic cough is based on the presence of the core clinical elements of tics such as suppressibility, distractibility, suggestibility, variability, and the presence of a premonitory sensation, whether the cough is a single tic or one of many (12). Tourette syndrome is a neuropsychiatric disorder characterized by the occurrence of involuntary motor and phonic tics such as coughing, grunting, and wheezing. These phonic tics can be misdiagnosed as respiratory disorders such as asthma, upper and lower respiratory tract infections. A careful history and thorough neurological examination are necessary to make a correct diagnosis. (13). When chronic cough is associated with cerebral manifestations such as truncal ataxia, nystagmus, or incoordination, a central cause should be suspected in the cough center or superior control area. Primary central causes of chronic cough are extremely rare. In patients with type-I Chiari malformations, cough may be the first symptom due to a lesion in the dorsal medullary region of the brainstem. A space-occupying lesion in the brainstem involving the cough center or pressing on the efferent fibers may be a rare cause of chronic cough (14).

\section{Cerebellar Disorders}

The neurons in the ventrolateral medulla that generate cough and breathing patterns interact with neural networks in the cerebellum-rostral interposed nucleus, the rostral fastigial nucleus, and the infra-cerebellar nucleus. Therefore, a dramatic reduction in cough frequency is observed after cerebellectomy or lesion of the interposed nucleus (15). In cerebellar neurodegenerative diseases, there is a reduction in the frequency of cough episodes that coincides with cerebellar atrophy. However, in a rare form of autosomal dominant cerebellar ataxia (spinocerebellar ataxia type-5), episodes of spasmodic cough begin 10 to 30 years earlier than the onset of ataxia. It may also be associated with spasmodic dysphonia and tremor. Both spasmodic cough and dysphonia may be caused by laryngeal hyperreactivity and vagal dysfunction. These coughing episodes could be considered reliable markers of familial neurodegenerative disease if there is a previously diagnosed case (16).

\section{Vagal neuropathy:}

Cough reflex hypersensitivity is manifested by the occurrence of coughing attacks, often triggered by lowthreshold stimuli to which the patient is exposed during normal daily activities. Cough reflex hypersensitivity is observed in all respiratory diseases (acute or chronic) when cough is a predominant feature. At the same time, neuroinflammation is one of the most important causes of cough reflex hypersensitivity (17). Cranial nerves, including the vagus nerve, may be affected by inflammatory neuropathic processes. The vagus nerve extensively innervates the respiratory and digestive tracts. Dysfunction of the vagus nerve can cause cough (18). 
Chronic neuropathy of the laryngopharyngeal nerve, which is a branch of the vagus nerve, manifests as symptoms of laryngeal irritation such as chronic cough, stridor, pharyngeal irritation, dysphonia, and foreign body sensation in the throat. In patients suffering from laryngeal neuropathy, there is increased sensitization of the cough reflex with abnormal neuropathic responses to receptor stimuli. Laryngopharyngeal neuropathy can lead to alterations in the afferent branches of the laryngeal and digestive reflex arcs. Consequently, various stimuli such as acids may trigger the symptoms. This may be accompanied by paradoxical vocal fold movements as part of a syndrome of irritated larynx, in which hypersensitivity of afferent reflexes is a common mechanism (19). Neuropathy of the vagus nerve may also affect other motor branches of the vagus nerve and cause paresis or paralysis of the vocal folds, paradoxical vocal fold movements, or other sensory branches causing chronic cough and other symptoms such as scratchy throat, sore throat, laryngeal paresthesias, and laryngospasm. These symptoms can be aggravated and provoked by talking, laughing, irritating inhalants, and palpation of the larynx (20).

Vagus nerve dysfunction may occur after viral infections or exposure to irritants or may be caused by chronic diseases such as asthma. In asthma, increased levels of substance $\mathrm{P}$ and neurokinin $\mathrm{A}$ in induced sputum samples are indicative of neuronal activation of the airways. Besides, levels of the neuropeptide calcitonin gene-related peptide (NCRP) in bronchoalveolar lavage from children with chronic cough are positively correlated with capsaicin cough reflex sensitivity. There is increased expression of NCRP in the nerves supplying the airways in patients with chronic cough (21). In diseases associated with persistent coughs, such as idiopathic pulmonary fibrosis, there are high levels of nerve growth factor in the airways of patients, which has important neuroinflammatory consequences and maybe one of the factors responsible for the chronicity of cough (22). Vitamin B12 deficiency can cause sensory neuropathy leading to dysfunction of the pharynx and larynx, which can trigger a chronic cough. Vitamin B12 supplementation can improve histamine threshold and significantly increase cough threshold in patients with chronic cough due to vitamin B12 deficiency but has no significant effect on individuals without deficiency (23). Vitamin B12 deficiencyrelated cough should be kept in mind in patients treated with proton pump inhibitors or cytotoxic drugs. Considering chronic cough as a neuropathic disorder, just like neuropathic chronic pain, will significantly change the possible strategies for the diagnosis and management of chronic cough (24).

\section{Neurological Conditions Associated with Diminished Cough Reflex Sensitivity:}

Because it is a reflex that predominantly involves the brainstem and is modulated by the cerebral cortex, the cough may be diminished in various neurologic disorders affecting both the peripheral and central nervous systems. A diminished cough reflex (dystonia) is associated with a high risk of developing pneumonia and an increased rate of morbidity and mortality in these disorders.

\section{Brain Hypoxia and Cerebrovascular Events:}

The central nervous system (CNS) is significantly affected by hypoxia, which can suppress the cough by various mechanisms, decreasing the sensitivity of the peripheral cough receptors and the sensitivity of the rostral and caudal parts of the nucleus solitaire. This nucleus is the recipient of all visceral afferents and an essential part of the regulatory centres of internal homeostasis, through its multiple projections with cardiorespiratory and gastrointestinal regulatory centres (25). The depressive effect of hypoxia on the nucleus solitaire is mediated through the gamma-aminobutyric acid (GABA)-mediated pathway. GABA is the major inhibitory neurotransmitter and can downregulate the sensitivity of the cough reflex. Therefore, baclofen, which is a GABA agonist, can decrease cough sensitivity to capsaicin in healthy individuals (26). Besides, hypoxia may increase CNS levels of endogenous opioids, thereby decreasing cough sensitivity by inhibiting the central component of cough. Hypoxia can occur in many cardiovascular diseases. Hypoxia-related impairment of the cough increases morbidity and mortality in these conditions (27). The cough reflex can be assessed in a comatose patient as part of Brainstem Responses Assessment Sedation Score (BRASS) in the ICU by observing the patient's response to tracheal suctioning. It is considered positive when contraction of the abdominal muscles is observed (28).

The cortex has its control over the cough. The ability to produce and suppress cough voluntarily are 
examples of cortical control of cough. Decreased strength of voluntary coughing may increase the risk of aspiration and other pulmonary sequelae due to inadequate clearance of aspirated material from the airways, as observed in patients with brainstem or cerebral stroke associated with an abnormal laryngeal cough reflex (29). Many patients with cerebral hemispheric stroke exhibit a transient or prolonged disturbance of the laryngeal cough reflex (known as "brainstem shock"). This shock is characterised by generalised transient or persistent neurologic dysfunction of one or more vital neurologic functions, including respiratory drive, the reticular activating system, or the laryngeal cough reflex. As a result, many patients with severe or mild hemispheric strokes may develop impaired consciousness and require intubation due to reduced respiratory drive (30). Daniels et al. showed that $67 \%$ of their patients with stroke had no cough response, and $38 \%$ had suffered aspiration (31). Therefore, adding cough sensitivity testing to the clinical assessment of swallowing function can significantly reduce the risk of aspiration pneumonia in patients with cerebral or brainstem stroke (32). It also helps monitor recovery from stroke and assesses postoperative recovery of the laryngeal cough reflex after extubation (29).

Patients with dementia due to Lewy body disease have decreased cough reflex sensitivity and central respiratory chemosensitivity, with decreased activation of the insula associated with the urge-to-cough (8). Patients with Parkinson's disease also have decreased intensity of both voluntary and reflex cough efforts with slightly increased cough threshold. Fontana et al. found that, especially in early stages, a motor rather than a sensory component of the cough reflex is involved, mainly due to impaired central activation of motor units and reduced neural control of expiratory muscles. This reflects the presence of bradykinesia, which is one of the most important dysfunctions in these patients (33). Parkinsonism is associated with decreased production of dopamine and other neurotransmitters in the substantia nigra, which affects the production of substance $\mathrm{P}$ in the $\mathrm{C}$ fibres of the vagal sensory nerve in the cervical ganglia. Low substance $\mathrm{P}$ levels weaken the swallowing reflex and suppress the cough reflex, leading to frequent aspiration (34). Approximately $20 \%$ of deaths in patients with Parkinsonism were related to pneumonia, likely due to the impaired cough reflex and upper airway muscle dysfunction (35). Similarly, multiple sclerosis, with its characteristic disseminated demyelination patches in both the brain and spinal cord, may impair voluntary cough efficiency and respiratory muscle strength due to bulbar dysfunction and damage to the corticospinal tract in the spinal cord. The degree of impairment of the cough reflex is inversely correlated with the degree of disability of the patients (36).

\section{Motor Neuron Diseases:}

Motor neuron disease is a neurological degenerative disorder affecting the corticospinal tracts, the motor nuclei in the brainstem, and the anterior horn cells of the spinal cord. It reduces the ability to cough efficiently. In the early stages, there is a hyperactive cough reflex due to the presence of inflammatory mediators such as bradykinin and prostaglandins. As the disease progresses, there is continuous damage that causes desensitisation of the cough. Various combinations of upper and lower motor neuron dysfunction can enhance the cough stimulus, but unfortunately, impair the efficiency of both volitional and reflex cough types (37). Amyotrophic lateral sclerosis is characterised by degeneration of the upper (UMN) and lower motor neurons (LMN), which negatively affects the ability of the respiratory and laryngeal muscles to work harmoniously during cough phases. The presence of stiffness due to UMN degeneration and weakness due to LMN degeneration results in abnormal cough flow and impaired ability to clear the airway, leading to various pulmonary sequelae, recurrent pneumonia, and even respiratory failure (38). The voluntary cough test detects the presence of dysphagia and impaired physiological capacity of airway clearance and secretion management (39).

\section{Neuromuscular Diseases:}

Neuromuscular diseases are associated with increased respiratory disturbances, including dysphagia, cough impairment, and frequent retching. In myasthenia gravis, there is cranial nerve impairment and bulbar weakness, which may be the initial symptoms that cause frequent aspiration, and consequently increase the frequency of coughing. However, if the patient develops respiratory insufficiency, the associated hypoxia causes peripheral and central impairment of cough reflex sensitivity (40). 


\section{Peripheral Neuropathy:}

Since cough is a defensive reflex, it could be affected by diseases targeting peripheral nerves. Consequently, vagotomy or anaesthesia-induced vagus block abolishes cough (41). Hereditary Sensory Autonomic Neuropathies (HSAN) are rare hereditary peripheral neuropathies characterized by loss of large myelinated and unmyelinated fibers resulting in decreased pain sensation. Congenital insensitivity to pain with anhidrosis (CIPA) is HSAN type-IV; it occurs because of a mutation in the gene encoding neurotrophic tyrosine kinase receptor type I (42). Both pain and cough can be elicited experimentally by stimulation of nociceptive C fibers as well as by faster conducting A $\delta$ fibers. Consequently, CIPA may affect both pain and cough (43).

Diabetic autonomic neuropathy is one of the most common complications of diabetes mellitus (DM). The vagus nerve is one of the first nerves to be DM damaged. Several studies showed a significant increase in cough threshold when the cough reflex was impaired. Ciljakova et al. found a strong negative correlation between cough reflex sensitivity and heart rate variability as an indicator of diabetic autonomic neuropathy (44). Downregulation of the cough reflex may begin very early in the pathogenesis of diabetes. Varechova et al. found decreased sensitivity of the cough reflex in children with type I DM with subclinical autonomic neuropathy. Testing these children for a decreased cough reflex may reflect the presence of autonomic dysfunction and its effects on breathing and general health (45). The sensitivity of the cough reflex could also decrease with age, during sleep, in the presence of cranial nerve conduction changes due to vitamin B12 and folate deficiency, and in the presence of inhibition of dopamine receptors by antipsychotic medications (34). Phrenic nerve paralysis or injury is associated with a decreased cough reflex (46).

\section{How can cough help to diagnose Neurologic disorders?}

\section{Arnold's nerve ear-cough reflex:}

In the Arnold's nerve ear cough reflex, the cough is induced by mechanical stimulation of the external auditory canal by the auricular branch of the vagus nerve (Arnold nerve). The test is performed with a cotton swab on a stick by stimulating the ear by inserting the swab 3 to $5 \mathrm{~mm}$ into the external auditory canal and rotating it for 2 to 3 seconds. The test is considered positive if the patient coughs within 10 seconds. The test should be performed on both sides, as many people have only one side affected. The test is positive in $2 \%$ of healthy children and adults, and in $3 \%$ of children and $25 \%$ of adults with a chronic cough. A positive reflex is more common in women than in men and is unilateral in over $90 \%$ of patients (47). Interestingly, hair in the ear canal can stimulate Arnold's nerve and trigger the cough reflex (ototricho-tussia). Such patients can be treated by simply removing the hair (48). This can be applied to any foreign body or earwax impaction in the ear canal. Therefore, examination of the external auditory canal should be routine in patients with chronic cough, especially in the elderly (49).

The high prevalence of positive Arnold nerve reflex in patients with chronic cough suggests that chronic cough is a neuropathic condition that may be secondary to sensory nerve damage. It is usually accompanied by other neuropathic features, such as throat irritation (laryngeal paresthesia). The cough is triggered by non-tussive triggers such as cold air and food (referred to as allotussia or urge-to-cough). The low prevalence of the positive reflex in children with chronic cough $(3 \%)$ compared with adults $(25 \%)$ suggests that the hypersensitivity of this reflex may have been acquired by viral infections (50).

Holmes-Adie syndrome is another rare cause of chronic cough; it is due to autonomic dysfunction involving the vagus nerve. Autonomic dysfunction is a common feature of this disorder; it is attributed to lesions of both afferent and efferent sympathetic and parasympathetic neurons. Airway reflux secondary to vagal dysfunction is a possible etiology of cough in these patients. Patients present with anisocoria, abnormal deep tendon reflexes, patchy areas of hyperhidrosis or anhidrosis, and chronic cough (51). Many patients with sensory neuropathic cough have been relieved by neuralgia Neuromodulator medications can help reduce or eliminate the cough by decreasing the "misfiring" of nerves caused by sensory neuropathic cough (52).

\section{Cough Syncope}

Cough syncope is a transient loss of consciousness with facial congestion and cyanosis; it typically occurs 
within seconds of a coughing attack, followed by rapid recovery. Cough syncope may originally mimic epilepsy. It was previously considered a form of epilepsy, called "laryngeal epilepsy" because of the jerky movements associated with it. However, many studies showed normal electrical activity of the brain during the episodes. It typically occurs in middle-aged and older male smokers, overweight or muscularly built with a history of chronic obstructive pulmonary disease. These individuals are more prone to produce very high intrathoracic pressure associated with cough-induced syncope and fainting (53). Because it is mainly a condition in adults, cough syncope has rarely been reported in children, especially in children younger than 10 years of age (54). The exact mechanism of cough syncope is controversial. Coughing markedly increases intrathoracic pressure and decreases cardiac output, thereby decreasing systemic blood pressure and causing cerebral hypoperfusion. At the same time, cerebrospinal fluid pressure increases, resulting in decreased cerebral perfusion; or there is a cerebral concussion-like effect due to the rapid rise in cerebrospinal fluid pressure. Another theory is that the cough triggers neurally mediated reflex vasodepressor bradycardia. Elimination of the cough eliminates the resulting syncopal episodes (55).

During the syncopal episode, the patient may have fixed upward deviation of the eyes, which should not be confused with epilepsy. The EEG shows transient slowing during the syncope but no seizure-like discharges. It is always associated with a coughing fit. The face becomes plethoric rather than cyanotic, and the entire episode lasts less than a minute. Syncope is never preceded by aura and is very rarely followed by postictal confusion/headache. Cough syncope usually occurs at night in the prone position, whereas epilepsy can occur in any position (56). Cough syncope is associated with a high incidence of pulmonary, cardiac, and neurologic disorders. Numerous CNS disorders have been associated with cough syncope, including cerebral tumors (meningioma, glioblastoma), herniation of cerebellar tonsils (type-1 Arnold-Chiari malformation), hydrocephalus, arterial occlusive disease of the carotid and vertebral arteries, basilar invagination, autosomal dominant hereditary sensory neuropathy, and medullary infarction (57).

\section{Cough Headache}

Cough-triggered headache is an uncommon finding, with a lifetime prevalence of $1 \%$. Headache can be triggered by rapid increase in the intra-abdominal, intra-thoracic, and intracranial pressure, caused by coughing, sneezing, or straining in patients with low pain threshold (58). It is either primary or symptomatic. Primary cough headache (previously known as benign cough headache or Valsalva-manoeuvre headache) is currently defined as a headache with sudden onset, occurring only in association with coughing, straining and/or Valsalva manoeuvre. It lasts from one second to 30 minutes and is not related to other disorder (59). It is more common in men over 40 years, and usually bilateral, but sometimes unilateral. Pain is of moderate-to-severe intensity and is usually located in the frontotemporal regions, but sometimes presents with different patterns as toothache. The pain can be triggered by Valsalva manoeuvrers, but never by physical exercise. Nausea, vomiting, photo- and phonophobia are uncommon (60).

Underlying disorders can be detected in $40 \%$ of cases with symptomatic cough headache. These lesions may involve but not limited to Chiari type I malformation, obstructive hydrocephalus, posterior fossa structural lesions (as arachnoid cysts, dermoid tumours, meningiomas, or osodontoideum), spontaneous low CSF pressure or leak, subdural hematoma, multiple brain metastases, acute sphenoid sinusitis, pneumocephalus, pneumococcal meningitis, or non-ruptured cerebral aneurysm (61). Symptoms are more common than observed with primary type, depending on the underlying abnormality. The headache is more intense with variable durations and locations. The pain may be pressing, explosive, bursting, stabbing, dull, electrical, lancinating, or having a mixed nature. Headache duration ranges from seconds to several weeks (58). Headache can be triggered by a cough as well as other triggering factors as laughing, exertion, weightlifting, defecation, or acute body or head postural changes. Posterior fossa symptoms like dizziness, unsteadiness, facial and upper limb numbness, vertigo, and syncope are common. The mechanism of headache is mostly due to the increase in intracranial pressure, supported by the fact that the headache disappears after the surgical correction of the lesion (62).

\section{Opioids-associated Cough:}


Opioids are known to have a central antitussive effect. However, some opioids, such as alfentanil, fentanyl, and sufentanil, can produce a brief tussive effect within a few seconds of rapid intravenous bolus injection in about $50 \%$ of patients (especially smokers). This is due to chemical stimulation of opioid receptors in the smooth muscle of the trachea, bronchi and bronchioles. It is unlikely that this pulmonary chemoreflex is mediated by the vagus nerve, as it is not affected by atropine pretreatment. Instead, pretreatment with an inhaled $\beta$-2-adrenergic agonist significantly reduces the rate of cough associated with intravenous opioid injection. This opioid-associated cough is usually self-limiting. It is also related to circulation time and could serve as a clinical cue for vein-to-brain time or cardiac output (63).

\section{Cough-anal reflex:}

Anal wink in response to cough or sniff is an important clinical sign on neurologic examination. It can be elicited by asking the patient to voluntarily cough or sniffle while observing the anus. This reflex is not affected by transection of the spinal cord, whereas it is lost in cauda equina lesions. It is easier to perform and more comfortable for the patient than the classic anal reflex. It is very promising and should be better included in the neurological examination (64).

\section{Conclusion:}

Cough is an important neurological sign, as well as an important respiratory sign. The sensitivity of the cough reflex may be increased or decreased in many neurologic conditions. Cough reflex testing is a quick, easy, and inexpensive test that can be performed during the cranial nerve exam.

\section{References:}

1. Canning BJ, Mori N, Mazzone SB. Vagal afferent nerves regulating the cough reflex. Respir Physiol Neurobiol. 2006 Jul 28;152(3):223-42. doi: 10.1016/j.resp.2006.03.001. PMID: 16740418.

2. Niimi A, Matsumoto H, Ueda T, Takemura M, Suzuki K, Tanaka E, Chin K, Mishima M, Amitani R. Impaired cough reflex in patients with recurrent pneumonia. Thorax. 2003 Feb;58(2):152-3. doi: 10.1136/thorax.58.2.152. PMID: 12554900.

3. Polverino M, Polverino F, Fasolino M, Andò F, Alfieri A, De Blasio F. Anatomy and neuropathophysiology of the cough reflex arc. Multidiscip Respir Med. 2012 Jun 18;7(1):5. doi: 10.1186/20496958-7-5. PMID: 22958367.

4. Monroe MD, Manco K, Bennett R, Huckabee M. Citric acid cough reflex test: stablishing normative data. Speech, Language and Hearing, 2014, 17:4, 216-24, https://doi.org/10.1179/2050572814Y.0000000041

5. Mills C, Jones R, Huckabee ML. Measuring voluntary and reflexive cough strength in healthy individuals. Respir Med. 2017 Nov;132:95-101. doi: 10.1016/j.rmed.2017.09.013. PMID: 29229113.

6. Miles A, Zeng IS, McLauchlan H, Huckabee ML. Cough reflex testing in Dysphagia following stroke: a randomized controlled trial. J Clin Med Res. 2013 Jun;5(3):222-33. doi: 10.4021/jocmr1340w. PMID: 23671548.

7. Fujiwara K, Kawamoto K, Shimizu Y, Fukuhara T, Koyama S, Kataoka H, Kitano H, Takeuchi H. A novel reflex cough testing device. BMC Pulm Med. 2017 Jan 18;17(1):19. doi: 10.1186/s12890-0170365-y. PMID: 28100202.

8. Ebihara T, Gui P, Ooyama C, Kozaki K, Ebihara S. Cough reflex sensitivity and urge-to-cough deterioration in dementia with Lewy bodies. ERJ Open Res. 2020 Mar 9;6(1):00108-2019. doi: 10.1183/23120541.00108-2019. PMID: 32166090.

9. Vertigan AE, Murad MH, Pringsheim T, Feinstein A, Chang AB, Newcombe PA, Rubin BK, McGarvey LP, Weir K, Altman KW, Weinberger M, Irwin RS, Adams TM, Altman KW, Barker AF, Birring SS, Blackhall F, Bolser DC, Boulet LP, Braman SS, Brightling C, Callahan-Lyon P, Canning BJ, Chang AB, Coeytaux R, Cowley T, Davenport P, Diekemper RL, Ebihara S, El Solh AA, Escalante P, Feinstein A, Field SK, Fisher D, French CT, Gibson P, Gold P, Gould MK, Grant C, Harding SM, Harnden A, Hill AT, Irwin RS, Kahrilas PJ, Keogh KA, Lane AP, Lim K, Malesker MA, Mazzone P, Mazzone S, McCrory DC, McGarvey L, Molasiotis A, Murad MH, Newcombe P, Nguyen HQ, Oppenheimer J, 
Prezant D, Pringsheim T, Restrepo MI, Rosen M, Rubin B, Ryu JH, Smith J, Tarlo SM, Vertigan AE, Wang G, Weinberger M, Weir K, Wiener RS; CHEST Expert Cough Panel. Somatic Cough Syndrome (Previously Referred to as Psychogenic Cough) and Tic Cough (Previously Referred to as Habit Cough) in Adults and Children: CHEST Guideline and Expert Panel Report. Chest. 2015 Jul;148(1):24-31. doi: 10.1378/chest.15-0423. PMID: 25856777.

10. Vertigan AE. Somatic cough syndrome or psychogenic cough-what is the difference? J Thorac Dis. 2017 Mar;9(3):831-838. doi: 10.21037/jtd.2017.03.119. PMID: 28449492; PMCID: PMC5394006.

11. Irwin RS, Glomb WB, Chang AB. Habit cough, tic cough, and psychogenic cough in adult and pediatric populations: ACCP evidence-based clinical practice guidelines. Chest. 2006 Jan;129(1 Suppl):174S179S. doi: 10.1378/chest.129.1_suppl.174S. PMID: 16428707.

12. Tan H, Büyükavci M, Arik A. Tourette's syndrome manifests as chronic persistent cough. Yonsei Med J. 2004 Feb 29;45(1):145-9. doi: 10.3349/ymj.2004.45.1.145. PMID: 15004882.

13. Perotin JM, Launois C, Dewolf M, Dumazet A, Dury S, Lebargy F, Dormoy V, Deslee G. Managing patients with chronic cough: challenges and solutions. Ther Clin Risk Manag. 2018 Jun 6;14:1041-1051. doi: 10.2147/TCRM.S136036. PMID: 29922064.

14. Williams SP, Bhutta MF. Chronic cough as a presenting feature of cerebral lymphoma. J Surg Case Rep. 2014 Oct 24;2014(10):rju109. doi: 10.1093/jscr/rju109. PMID: 25344556.

15. Xu F, Frazier DT. Role of the cerebellar deep nuclei in respiratory modulation. Cerebellum. 2002 Jan-Mar;1(1):35-40. doi: 10.1080/147342202753203078. PMID: 12879972.

16. Coutinho P, Cruz VT, Tuna A, Silva SE, Guimarães J. Cerebellar ataxia with spasmodic cough: a new form of dominant ataxia. Arch Neurol. 2006 Apr;63(4):553-5. doi: 10.1001/archneur.63.4.553. PMID: 16606768 .

17. Sacre-Hazouri JA, Sacre L. Tos crónica. Síndrome de hipersensibilidad del reflejo de la tos [Chronic cough. Cough reflex hypersensitivity syndrome]. Rev Alerg Mex. 2019 Apr-Jun;66(2):217-231. Spanish. doi: 10.29262/ram.v66i2.565. PMID: 31200420.

18. Amin MR, Koufman JA. Vagal neuropathy after upper respiratory infection: a viral etiology? Am J Otolaryngol. 2001 Jul-Aug;22(4):251-6. doi: 10.1053/ajot.2001.24823. PMID: 11464321.

19. Benninger MS, Campagnolo A. Chronic laryngopharyngeal vagal neuropathy. Braz J Otorhinolaryngol. 2018 Jul-Aug;84(4):401-403. doi: 10.1016/j.bjorl.2018.04.001. Epub 2018 Apr 24. PMID: 29853310.

20. Pacheco A, Cobeta I. Refractory chronic cough, or the need to focus on the relationship between the larynx and the esophagus. Cough. 2013 Apr 3;9(1):10. doi: 10.1186/1745-9974-9-10. PMID: 23552099.

21. Chung KF. Approach to chronic cough: the neuropathic basis for cough hypersensitivity syndrome. J Thorac Dis. 2014 Oct;6(Suppl 7):S699-707. doi: 10.3978/j.issn.2072-1439.2014.08.41. PMID: 25383203.

22. Hope-Gill BD, Hilldrup S, Davies C, Newton RP, Harrison NK. A study of the cough reflex in idiopathic pulmonary fibrosis. Am J Respir Crit Care Med. 2003 Oct 15;168(8):995-1002. doi: 10.1164/rccm.200304-597OC. PMID: 12917229.

23. Bucca CB, Culla B, Guida G, Sciascia S, Bellone G, Moretto A, Heffler E, Bugiani M, Rolla G, Brussino L. Unexplained chronic cough and vitamin B-12 deficiency. Am J Clin Nutr. 2011 Mar;93(3):542-8. doi: 10.3945/ajcn.110.000802. PMID: 21248188.

24. Cho YS. Now is the Right Time to Establish a New Strategy for Managing Chronic Cough as a Neuropathic Disorder. Allergy Asthma Immunol Res. 2014 Sep;6(5):373-5. doi: 10.4168/aair.2014.6.5.373. PMID: 25228993.

25. Baker E, Lui F. Neuroanatomy, Vagal Nerve Nuclei (Nucleus Vagus). 2020 Jul 31. In: StatPearls [Internet]. Treasure Island (FL): StatPearls Publishing; 2020 Jan-. PMID: 31424793.

26. Tabata M, Kurosawa H, Kikuchi Y, Hida W, Ogawa H, Okabe S, Tun Y, Hattori T, Shirato K. Role of GABA within the nucleus tractus solitarii in the hypoxic ventilatory decline of awake rats. Am J Physiol Regul Integr Comp Physiol. 2001 Nov;281(5):R1411-9. doi: 10.1152/ajpregu.2001.281.5.R1411. PMID: 11641110.

27. Eckert DJ, Catcheside PG, Stadler DL, McDonald R, Hlavac MC, McEvoy RD. Acute sustained hypoxia suppresses the cough reflex in healthy subjects. Am J Respir Crit Care Med. 2006 Mar 1;173(5):506-11. doi: 10.1164/rccm.200509-1455OC. PMID: 16322644. 
28. Rohaut B, Porcher R, Hissem T, Heming N, Chillet P, Djedaini K, Moneger G, Kandelman S, Allary J, Cariou A, Sonneville R, Polito A, Antona M, Azabou E, Annane D, Siami S, Chrétien F, Mantz J, Sharshar T; Groupe d'Exploration Neurologique en Réanimation (GENER). Brainstem response patterns in deeply-sedated critically-ill patients predict 28-day mortality. PLoS One. 2017 Apr 25;12(4):e0176012. doi: 10.1371/journal.pone.0176012. PMID: 28441453.

29. Addington WR, Stephens RE, Gilliland K, Rodriguez M. Assessing the laryngeal cough reflex and the risk of developing pneumonia after stroke. Arch Phys Med Rehabil. 1999 Feb;80(2):150-4. doi: 10.1016/s0003-9993(99)90112-0. PMID: 10025488.

30. Addington WR, Stephens RE, Widdicombe JG, Rekab K. Effect of stroke location on the laryngeal cough reflex and pneumonia risk. Cough. 2005 Aug 4;1:4. doi: 10.1186/1745-9974-1-4. PMID: 16270928.

31. Daniels SK, Brailey K, Priestly DH, Herrington LR, Weisberg LA, Foundas AL. Aspiration in patients with acute stroke. Arch Phys Med Rehabil. 1998 Jan;79(1):14-9. doi: 10.1016/s0003-9993(98)90200-3. PMID: 9440410.

32. Miles A, Zeng IS, McLauchlan H, Huckabee ML. Cough reflex testing in Dysphagia following stroke: a randomized controlled trial. J Clin Med Res. 2013 Jun;5(3):222-33. doi: 10.4021/jocmr1340w. PMID: 23671548.

33. Fontana GA, Pantaleo T, Lavorini F, Benvenuti F, Gangemi S. Defective motor control of coughing in Parkinson's disease. Am J Respir Crit Care Med. 1998 Aug;158(2):458-64. doi: 10.1164/ajrccm.158.2.9705094. PMID: 9700121.

34. The committee for The Japanese Respiratory Society guidelines for management of cough. Mechanism of cough. Respirology, 2006, 11: S4, S137-S 139. https://doi.org/10.1111/j.1440-1843.2006.00920_2.x

35. Mangera Z, Panesar G, Makker H. Practical approach to management of respiratory complications in neurological disorders. Int J Gen Med. 2012;5:255-63. doi: 10.2147/IJGM.S26333. PMID: 22505823.

36. Aiello M, Rampello A, Granella F, Maestrelli M, Tzani P, Immovilli P, Franceschini M, Olivieri D, Chetta A: Cough Efficacy Is Related to the Disability Status in Patients with Multiple Sclerosis. Respiration 2008;76:311-316. doi: 10.1159/000119641. PMID: 18319585

37. Hadjikoutis S, Wiles CM, Eccles R. Cough in motor neuron disease: a review of mechanisms. QJM. 1999 Sep;92(9):487-94. doi: 10.1093/qjmed/92.9.487. PMID: 10627867.

38. Kim WH, Kim JH, Kim EK, Yun SP, Kim KK, Kim WC, Jeong HC. Myasthenia gravis presenting as isolated respiratory failure: a case report. Korean J Intern Med. 2010 Mar;25(1):101-4. doi: 10.3904/kjim.2010.25.1.101. PMID: 20195411.

39. Tabor-Gray LC, Gallestagui A, Vasilopoulos T, Plowman EK. Characteristics of impaired voluntary cough function in individuals with amyotrophic lateral sclerosis. Amyotroph Lateral Scler Frontotemporal Degener. 2019 Feb;20(1-2):37-42. doi: 10.1080/21678421.2018.1510011. PMID: 30652513.

40. Rafiq MK, Bradburn M, Mustfa N, McDermott CJ, Annane D. Mechanical cough augmentation techniques in amyotrophic lateral sclerosis/motor neuron disease. Cochrane Database Syst Rev. 2016 Dec 23;2016(12):CD012482. doi: 10.1002/14651858.CD012482.

41. Woodcock A, Young EC, Smith JA. New insights in cough. Br Med Bull. 2010;96:61-73. doi: 10.1093/bmb/ldq034. PMID: 21030396.

42. Sasnur AH, Sasnur PA, Ghaus-Ul RS. Congenital insensitivity to pain and anhidrosis. Indian J Orthop. 2011 May;45(3):269-71. doi: 10.4103/0019-5413.80047. PMID: 21559108.

43. Gracely RH, Undem BJ, Banzett RB. Cough, pain and dyspnoea: similarities and differences. Pulm Pharmacol Ther. 2007;20(4):433-7. doi: 10.1016/j.pupt.2006.12.005. PMID: 17336558.

44. Ciljakova M, Vojtkova J, Durdik P, Turcan T, Petrikova M, Michnova Z, Banovcin P. Cough reflex sensitivity in adolescents with diabetic autonomic neuropathy. Eur J Med Res. 2009 Dec 7;14 Suppl 4(Suppl 4):45-8. doi: 10.1186/2047-783x-14-s4-45. PMID: 20156724; PMCID: PMC3521379.

45. Varechova S, Durdik P, Cervenkova V, Ciljakova M, Banovcin P, Hanacek J. The influence of autonomic neuropathy on cough reflex sensitivity in children with diabetes mellitus type 1. J Physiol Pharmacol. 2007 Nov;58 Suppl 5(Pt 2):705-15. PMID: 18204186.

46. Prasad S, Athreya BH. Transient paralysis of the phrenic nerve associated with head injury. JAMA. 1976 Nov 29;236(22):2532-3. PMID: 1036522. 
47. Dicpinigaitis PV, Kantar A, Enilari O, Paravati F. Prevalence of Arnold Nerve Reflex in Adults and Children With Chronic Cough. Chest. 2018 Mar;153(3):675-679. doi: 10.1016/j.chest.2017.11.019. PMID: 29197546.

48. Castro RA, Zalvan CH, Berzofsky C. Oto-tricho-tussia: An Unexpected Cause of Cough. Case Rep Otolaryngol. 2020 Mar 31;2020:3527481. doi: 10.1155/2020/3527481. PMID: 32292619.

49. Gold KR, Wester JL, Gold R. Foreign Body in External Ear Canal: An Unusual Cause of Chronic Cough. Am J Med. 2017 Apr;130(4):e143-e144. doi: 10.1016/j.amjmed.2016.11.026. PMID: 28159186.

50. Ryan NM, Gibson PG, Birring SS. Arnold's nerve cough reflex: evidence for chronic cough as a sensory vagal neuropathy. J Thorac Dis. 2014 Oct;6(Suppl 7):S748-52. doi: 10.3978/j.issn.2072-1439.2014.04.22. PMID: 25383210.

51. Kimber J, Mitchell D, Mathias CJ. Chronic cough in the Holmes-Adie syndrome: association in five cases with autonomic dysfunction. J Neurol Neurosurg Psychiatry. 1998 Oct;65(4):583-6. doi: 10.1136/jnnp.65.4.583. PMID: 9771793.

52. Shi G, Shen Q, Zhang C, Ma J, Mohammed A, Zhao H. Efficacy and Safety of Gabapentin in the Treatment of Chronic Cough: A Systematic Review. Tuberc Respir Dis (Seoul). 2018 Jul;81(3):167174. doi: 10.4046/trd.2017.0089. Epub 2018 Jun 19. PMID: 29926540; PMCID: PMC6030663.

53. Waldmann V, Combes N, Narayanan K, Sharifzadehgan A, Bouzeman A, Beganton F, Combes S, Albenque JP, Boveda S, Marijon E. Cough Syncope. Am J Med. 2017 Jul;130(7):e295-e296. doi: 10.1016/j.amjmed.2017.01.050. Epub 2017 Feb 27. PMID: 28238688.

54. Katz RM. Cough syncope in children with asthma. J Pediatr. 1970 Jul;77(1):48-51. doi: 10.1016/s00223476(70)80043-9. PMID: 5430795.

55. Anand Deshmukh, Dan Schulle. Cough syncope in a patient with severe chronic obstructive pulmonary disease. Respiratory Medicine CME, 2008; 1: (2), 120-122. Doi: 10.1016/j.rmedc.2008.01.004.

56. Haslam RH, Freigang B. Cough syncope mimicking epilepsy in asthmatic children. Can J Neurol Sci. 1985 Feb;12(1):45-7. doi: 10.1017/s0317167100046576. PMID: 3978474.

57. Dicpinigaitis PV, Lim L, Farmakidis C. Cough syncope. Respir Med. 2014 Feb;108(2):244-51. doi: 10.1016/j.rmed.2013.10.020. Epub 2013 Nov 5. PMID: 24238768.

58. Chen PK, Fuh JL, Wang SJ. Cough headache: a study of 83 consecutive patients. Cephalalgia. 2009 Oct;29(10):1079-85. doi: 10.1111/j.1468-2982.2009.01844.x. PMID: 19438909.

59. Headache Classification Subcommittee of the International Headache Society. The International Classification of Headache Disorders: 2nd edition. Cephalalgia. 2004;24 Suppl 1:9-160. doi: 10.1111/j.14682982.2003.00824.x. PMID: 14979299.

60. Pascual J, González-Mandly A, Martín R, Oterino A. Headaches precipitated by cough, prolonged exercise or sexual activity: a prospective etiological and clinical study. J Headache Pain. 2008 Oct;9(5):25966. doi: 10.1007/s10194-008-0063-5. PMID: 18751938.

61. Cordenier A, De Hertogh W, De Keyser J, Versijpt J. Headache associated with cough: a review. J Headache Pain. 2013 May 20;14(1):42. doi: 10.1186/1129-2377-14-42. PMID: 23687906.

62. Sansur CA, Heiss JD, DeVroom HL, Eskioglu E, Ennis R, Oldfield EH. Pathophysiology of headache associated with cough in patients with Chiari I malformation. J Neurosurg. 2003 Mar;98(3):453-8. doi: 10.3171/jns.2003.98.3.0453. PMID: 12650413.

63. Bailey PL. Possible mechanism(s) of opioid-induced coughing. Anesthesiology. 1999 Jan;90(1):335. doi: 10.1097/00000542-199901000-00067. PMID: 9915357.

64. Chan CL, Ponsford S, Swash M. The anal reflex elicited by cough and sniff: validation of a neglected clinical sign. J Neurol Neurosurg Psychiatry. 2004 Oct;75(10):1449-51. doi: 10.1136/jnnp.2003.032110. PMID: 1537769.

\section{Hosted file}

Table 1.pdf available at https://authorea.com/users/361350/articles/509495-cough-as-aneurological-sign-does-it-worth-it 